\title{
PENERAPAN PRINSIP FENG SHUI PADA KAPLING DAN BANGUNAN RUMAH DI PERUMAHAN SURABAYA
}

\author{
Angeline Wijaya ${ }^{1}$, Timoticin Kwanda², Jani Rahardjo ${ }^{3}$
}

\begin{abstract}
ABSTRAK: Feng shui adalah sebuah ilmu yang mempelajari bagaimana cara manusia untuk hidup selaras dengan alam dan lingkungan sekitar. Prinsip feng shui pada dasarnya sederhana, karena mengikuti pola yin yang atau keseimbangan. Sehingga dengan penerapan nilai-nilai feng shui yang baik pada rumah tinggal, maka akan memberikan kenyamanan bagi penghuni rumah dan memberikan nilai serta harga jual yang lebih tinggi. Perumusan masalah dari penelitian ini adalah untuk mengetahui seberapa dalam faktor feng shui yang dipertimbangkan oleh penghuni. Kemudian mencari adanya hubungan antara unsur feng shui yang dipercaya dengan penerapan terhadap penyelesaian masalah feng shui secara desain dan non-desain. Chi square digunakan untuk melihat apakah ada hubungan antara prinsip feng shui dengan aplikasinya. Hasil yang ditemukan menunjukkan bahwa faktor feng shui yang paling dipertimbangkan oleh penghuni rumah tinggal yang bermasalah menurut prinsip feng shui adalah faktor denah rumah. Dan didapatkan hasil yang menyatakan bahwa adanya hubungan antara kepercayaan terhadap faktor feng shui dengan penerapan pada faktor bentuk kapling, faktor benda di sekitar bangunan, faktor posisi rumah terhadap jalan, faktor bentuk bangunan, faktor denah rumah, dan faktor nomor rumah, cermin feng shui dan ba gua.
\end{abstract}

Kata kunci : fengshui, keseimbangan, kapling, bangunan rumah, perumahan

ABSTRACT: Feng shui is a science that studies how humans live in harmony with nature. The principle of feng shui is basically simple, because it follows a yin yang or balance. With the right application of feng shui in residential, it will comfort the residents and provide value and make the property prices increase. The problem of this research is the to know how the resident consid the feng shui factors. Then find for a relationship between feng shui elements applied to solving feng shui problems in design and non-design. Chi square method is used to see if there is any relationship between feng shui principle and its application. The findings show that the most considered feng shui factor by the residents of the troubled home according to feng shui principle is the house plan factor. And the result shows that there is a relation between feng shui factor with application on plot factor, object around building factor, Position of the house against the road factor, building form factor, house plan factor and house number, feng shui mirror and Ba gua factor.

Keywords : fengshui, balance, plot, house, residential

${ }^{1}$ Mahasiswa Program Studi Magister $\quad$ Teknik Sipil Universitas Kristen Petra,
angelinethresdy@gmail.com
${ }^{2}$ Dosen Program Studi Magister Teknik Sipil Universitas Kristen Petra, cornelia@petra.ac.id
30




\section{PENDAHULUAN}

Perkembangan teknologi mempengaruhi kebutuhan akan sebuah rumah tinggal, namun masih ada faktor tradisional yang tidak ditinggalkan dan dilupakan yaitu feng shui. Feng shui mempelajari bagaimana cara manusia untuk hidup selaras dengan alam dan lingkungan sekitar. Feng shui merupakan salah satu faktor yang mempengaruhi konsumen dalam menentukan pilihan rumah tinggal (Anindita, Setijanti, \& Rachmawati, 2014). Pengaplikasian feng shui dapat mempengaruhi nilai faktor pemasarannya (Kurniawan, 2015). Rumah dengan feng shui yang baik serta dengan harga jual yang lebih mahal akan dapat diterima oleh konsumen (Anindita, Setijanti, \& Rachmawati. 2014). Penerapan nilai-nilai feng shui yang baik akan memberikan kenyamanan bagi penghuninya serta memberikan nilai dan harga jual yang lebih tinggi (Roberts, 2006). Diharapkan para pengembang kawasan perumahan dapat mempertimbangkan unsur feng shui sebagai salah satu strategi yang cukup efisien dalam mendesain suatu kawasan perumahan untuk memenangkan hati konsumen. Oleh karena itu penulis ingin mencari tahu seberapa penting penerapan di dalam desain berdasarkan prinsip feng shui ditinjau dari sudut pandang pemilik atau penghuni rumah tinggal itu sendiri. Dalam penelitian ini, akan dibahas tentang adanya hubungan antara kepercayaan terhadap prinsip feng shui dengan penerapannya.

\section{TINJAUAN PUSTAKA}

Feng shui merupakan seni Cina kuno dan ilmu penempatan obyek dalam ruang untuk menciptakan aliran energi yang sehat, yang disebut "qi". Feng shui merupakan suatu hubungan yang seimbang dengan alam dan hubungan antara satu sama lain untuk menciptakan suatu kesinambungan yang baik di dalam praktek maupun di dalam prinsipnya sehingga menciptakan dampak yang baik bagi alam dan manusia (Choy,n.d). Prinsip feng shui yang perlu dipertimbangkan di dalam penerapannya sebagai berikut :

- Bentuk kapling yang baik menurut feng shui adala bentuka kapling persegi dan persegi panjang, sedangkan bentuk kapling yang tidak baik adalah bentuk kapling segitiga. (Skillon, 2008).

- Posisi pintu utama yang menghadap saluran pembuangan sistem penyejuk udara atau AC dan generator, tiang listrik, segitiga dari sisi atap meruncing dari gedung sekitar, dan lampu jalan atau lalu lintas dapat memberikan efek negatif bagi kesehatan penghuni (Harjanto, 2008, p.55-67).

- Posisi rumah terhadap jalan dianggap baik jika terletak di ujung serangkaian loop di jalan berkelok-kelok dari lingkaran lalu lintas, material krikil dan tanah. Dianggap tidak baik jika terletak pada $T$-junction (tusuk sate) dan persimpangan $\mathrm{Y}$, dekat landasan bandara, kanal, dinding, di dekat jembatan, viaduk, jalan layang atau cekung, simpang susun jalan raya, dekat tikungan tajam atau berjalan panjang, terletak di jalan buntu dan cul-de-sac, pada jalan sudut karena energi yang ada pada posisi ini terlalu besar, pada posisi jalan raya yang lebih tinggi dari tapak (Harjanto, 2008).

- Orientasi ruang pada rumah dapat membantu di dalam beberapa aspek yang dimana masing-masing arahnya memiliki fungsi berbeda sesuai dengan yang dibutuhkan.

- Bentuk bangunan yang dianggap tidak baik di dalam feng shui adalaha bangunan berbentuk $\mathrm{L}$ dan $U$ karena bagian tengah dari rumah merupakan jantung rumah, dan hal ini tidak utuh apabila rumah berbentuk $L$ atau $U$.

- Di dalam feng shui juga perlu memperhatikan tatanan ruangan di dalam bangunan. Sehingga dengan penataan yang baik maka diharapkan akan menimbulkan kenyamanan bagi penghuni. (Ziegler, 2001). Terutama untuk penataan pintu masuk, ruang tamu, kamar tidur, kamar mandi, dapur, ruang makan, dan perhitungan anak tangga dan peletakkannya.

- Atap dan pagar pada sebuah rumah merupakan hal yang perlu diperhatikan, karena 2 elemen itu memiliki fungsi sebagai penjaga dan pelindung dari segala energi negatif dari luar serta dapat menahan energi chi negatif masuk ke dalam rumah. Retakan pada tembok yang diakibatkan karena kegagalan struktural yang disebabkan oleh konstruksi atap dapat 
menyebabkan adanya lubang angin, yang dimana menurut ilmu feng shui hal ini dapat mengakibatkan sebuah rumah tersebut sering dihantam oleh angin dan otomatis kehilangan chi positif (Dian, 2012).

- Nomor rumah yang dianggap baik adalah 3,6,8,9, sedangkan yang dianggap sial adalah nomor 4. Cermin feng shui memiliki pengaruh dalam menangkap atau memantulkan sebuah energi. Ba gua terdiri dari 2 jenis, yaitu xian tian ba gua dan huo tian ba gua. Xian tian ba gua juga disebut dengan yin ba gua sedangkan huo tian ba gua disebut dengan yang ba gua. Fungsi dari ba gua yaitu untuk menangkis segala macam energi yang buruk, seperti sudut runcing bangunan tetangga, jalan tusuk sate, sampai untuk menangkis serangan ilmu hitam (Bourassa dan Peng 1999).

- Di dalam artikel "The Retail Recipe for Great Feng shui", menjelaskan lima elemen feng shui yang terdiri dari kayu, api, tanah, logam, dan air. Kelima elemen ini memiliki hubungan satu sama lain dan menciptakan sebuah harmoni. Lima elemen ini memiliki arti dan dapat menstimulus perasaan tertentu bagi yang melihatnya (Collins, 2015)

\section{METODOLOGI PENELITIAN}

Penelitian ini dilakukan dengan menyebarkan kuesioner kepada responden dengan jumlah 68 responden yang berperan sebagai penghuni unit rumah tersebut. Teknik penarikan kuisioner dilakukan dengan cara mengisi kuisioner baik secara online maupun secara offline Data yang didapatkan dari hasil kuesioner akan dianalisa dengan bantuan program SPSS berupa analisa deskriptif dan frekuensi jawaban responden.

\section{ANALISIS DAN PEMBAHASAN}

\subsection{Gambaran Umum Obyek Penelitian}

Penelitian yang akan dilakukan adalah mengenai seberapa dalam prinsip feng shui dipertimbangkan oleh penghuni rumah tersebut, serta melihat apakah ada hubungan antara prinsip feng shui dengan penerapannya. Objek pada penelitian adalah responden pemilik rumah tinggal yang berada pada kawasan perumahan Surabaya. Kuesioner disebarkan kepada pihak terkait sejak bulan Maret 2017 hingga awal bulan Juni 2017, dengan jumlah 68 responden.

\subsection{Uji Validitas Kuesioner}

Uji validitas digunakan untuk mengukur sah atau valid tidaknya suatu kuesioner. Langkah dalam menguji validitas butir pertanyaan pada kuesioner yaitu mencari nilai corrected ltemTotal correlation. Setiap pernyataan dinyatakan valid apabila corrected item total correlation yang dihasilkan di atas r-tabel, yaitu sebesar 0.2387. Dapat diketahui bahwa indikator yang tidak memenuhi nilai corrected item-total correlation $n>0.2387$, yaitu indikator bentuk kapling persegi dianggap baik dan variabel atap dan pagar. Dilakukan penghapusan terhadap indikator tersebut, sehingga diperoleh pertanyaan kuesioner yang telah valid dan mampu mengukur tiap variabel yang digunakan dalam penelitian ini.

\subsection{Uji Reliabilitas Kuesioner}

Hasil pengolahan data menyatakan bahwa faktor bentuk kapling memiliki tingkat reabilitas sedang dengan nilai cronbach alpha 0,541. Pada faktor benda di sekitar bangunan dengan nilai cronbach alpha 0,764 , faktor posisi rumah terhadap jalan dengan nilai cronbach alpha 0,731, faktor bentuk bangunan dengan nilai cronbach alpha 0,783 , faktor nomor rumah, cermin feng shui dan cermin ba gua dengan nilai cronbach alpha 0,783 , faktor unsur dan warna di dalam feng shui dengan nilai cronbach alpha 0,829 memiliki tingkat reabilitas tinggi. Pada faktor orientasi ruangan rumah memiliki tingkat reabilitas sangat tinggi dengan nilai cronbach alpha 0,957. 


\subsection{Analisa Tingkat Kepentingan Pertimbangan Unsur Feng Shui 4.4.1. Analisa Faktor Unsur Feng Shui yang Berpengaruh}

Untuk faktor bentuk kapling dapat digolongkan di dalam 1 kelompok, untuk faktor benda di seskitar bangunan dapat digolongkan menjadi 1 kelompok, faktor posisi rumah terhadap jalan dapat digolongkan menjadi 2 kelompok, faktor orientasi ruang pada rumah digolongkan menjadi 1 kelompok, untuk faktor bentuk bangunan digolongkan menjadi 1 kelompok, untuk faktor denah rumah digolongkan menjadi 3 kelompok, faktor nomor rumah, cermin feng shui dan ba gua digolongkan menjadi 1 kelompok, dan yang terakhir untuk faktor unsur dan warna di dalam feng shui dapat digolongkan menjadi 1 kelompok.

\subsubsection{Analisa Mean Faktor Feng Shui yang Berpengaruh}

Dari kedelapan faktor feng shui tersebut didapatkan hasil bahwa faktor denah rumah kelompok $2(4,5882)$ merupakan faktor yang paling dipertimbangkan oleh penghuni rumah. Kemudian diikuti juga dengan faktor denah rumah kelompok $1(4,2996)$, nomor rumah, cermin feng shui dan ba gua (4.034), faktor benda di sekitar bangunan (3.9288), faktor posisi rumah terhadap jalan kelompok 2 (3.9485), faktor bentuk kapling (3.8971), faktor orientasi ruang pada rumah (3.832), faktor denah rumah kelompok 3 (3.8235), faktor unsur dan warna di dalam feng shui (3.8206), faktor posisi rumah terhadap jalan kelompok 1 (3.7941), dan terakhir faktor bentuk bangunan (3.7684).

\subsubsection{Uji Chi Square Faktor Feng Shui dengan Penerapan Penyelesaian Masalah dari Segi Feng Shui}

Adanya hubungan antara faktor feng shui bentuk kapling dengan penerapannya dengan nilai signifikansi sebesar 0,010 .

Nilai signifikansi faktor benda di sekitar bangunan pada dengan variabel 2.1 (0.011) dan variabel 2,3 (0.011) sehingga dapat disimpulkan bahwa adanya hubungan antara kepercayaan faktor feng shui dengan penerapannya. Namun hal ini berbeda dengan variabel 2.2 dimana nilai signifikansinya 0.107 , sehingga tidak adanya hubungan.

Posisi rumah terhadap jalan (kelompok 1) menunjukkan hasil yang menyatakan bahwa adanya hubungan antara prinsip feng shui dengan penerapannya pada penyesuai desain rumah pada tikungan tajam dengan nilai signifikansi 0.044 . Untuk posisi rumah terhadap jalan (kelompok 2) pada Tabel 4.13 menunjukkan adanya hubungan antara faktor feng shui dengan penerapan pada desain bangunan yang terletak di antara 2 jalan pararel dengan nilai signifikansi 0.015 dan bangunan pada tikungan tajam dengan nilai signifikansi 0.017 .

Faktor bentuk bangunan memiliki hubungan dengan penerapan prinsip feng shui pada desain bangunan segitiga tidak dipilih sebagai rumah tinggal dengan nilai signifikansi 0.026 .

Hasil denah rumah (kelompok 1) terlihat hasil bahwa adanya hubungan antara prinsip feng shui dengan penerapannya pada letak pintu masuk dengan nilai signifikasi 0.038 , penataan ruang tamu dengan nilai signifikansi 0.013 , penataan letak posisi dapur dengan nilai signifikansi 0.042, dan perhitungan jumlah anak tangga dengan nilai signifikansi 0.032 .

Hasil denah rumah (kelompok 2) terlihat hasil bahwa tidak adanya hubungan antara prinsip feng shui dengan penerapannya. Untuk denah rumah (kelompok 3) terlihat hasil bahwa adanya hubungan antara prinsip feng shui dengan penerapannya pada penyesuaian bentuk tangga dengan nilai signifikansi 0.012 , dan perhitungan jumlah anak tangga dengan nilai signifikansi 0.022 .

Hasil faktor nomor rumah, cermin feng shui dan ba gua menunjukkan adanya hubungan antara prinsip feng shui dengan penerapannya. Hal itu terlihat pada pemilihan nomor rumah dengan unsur 3,6,8,9 dengan nilai signifikansi 0.019 , tidak memilih nomor rumah angka 4 dengan signifikansi 0.000 , melakukan pemasangan cermin feng shui dengan signifikansi 0.003 , dan pemasangan cermin ba gua dengan signifikansi 0.002 . 


\section{KESIMPULAN DAN SARAN}

\subsection{Kesimpulan}

Berdasarkan hasil penelitian mengenai penerapan prinsip feng shui pada kapling dan bangunan rumah di perumahan Surabaya, peneliti dapat menyimpulkan bahwa prinsip feng shui yang paling dipertimbangkan oleh penghuni rumah tinggal yang bermasalah menurut prinsip feng shui adalah faktor denah rumah.

Hasil penelitian menyatakan adanya hubungan antara faktor feng shui dengan penerapan penyelesaian masalah pada bentuk kapling, penerapan penyelesaian masalah pada bendabenda di sekitar bangunan, penerapan penyelesaian masalah pada posisi rumah terhadap jalan, penerapan penyelesaian masalah pada bentuk bangunan, penerapan penyelesaian masalah pada denah rumah, penerapan penyelesaian masalah pada nomor rumah, cermin feng shui dan ba gua.

Dari hasil penelitian ini juga menyatakan bahwa tidak adanya hubungan antara kepercayaan pada prinsip feng shui tentang orientasi ruangan pada rumah, serta warna dan unsur di dalam feng shui dengan penerapan masalah prinsip feng shui.

\subsection{Saran}

\subsubsection{Untuk Penelitian Selanjutnya}

Disarankan agar menambahkan pertanyaan tentang usia responden, dan faktor unsur feng shui lainnya yang belum diteliti dalam penelitian ini sebagai contohnya bentuk kapling trapesium, jajaran genjang, bentuk $L$, bentuk $T$, dan bentuk yang tidak beraturan. Dapat ditambahkan juga faktor tentang sejarah lokasi tersebut sebelum dirubah menjadi perumahan, karena dalam feng shui sejarah kapling seperti halnya kapling bekas rumah sakit, kantor polisi, tempat ibadah, rumah potong hewan, rumah pemakaman dapat menimbulkan energi negatif yang dihubungkan dan diturunkan oleh kegiatan yang pernah dilakukan sebelumnya di tempat tersebut, sebab dalam ilmu feng shui, energi dari lokasi di atas disebut dengan 'Yin sha' atau energi yang dingin dan dapat berpengaruh buruk pada kesehatan dan keberuntungan penghuninya.

Selain itu, diharapkan ada penelitian lanjutan mengenai pengaplikasian unsur feng shui tersebut terhadap desain suatu kawasan perumahan dari sisi pengembang. Seperti halnya dalam penataan site plan, terutama dalam pemilihan pola jalan, pemilihan dan penataan benda-benda di sekitar bangunan, elemen-elemen vegetasi, penataan sistem utilitas yang baik yang sesuai dengan prinsip feng shui untuk menciptakan suatu tatanan kawasan yang dapat menimbulkan suatu kenyamanan bagi para penghuninya.

\subsubsection{Untuk Perencana, Desainer Interior dan Pengembang}

Hasil penelitian ini menyatakan bahwa faktor denah rumah merupakan faktor yang paling diperhatikan oleh penghuni, sehingga hal tersebut dapat menjadi pertimbangan dalam mendesain tata letak sebuah ruangan, khususnya untuk letak posisi pintu masuk dengan aksesbilitas yang baik, bentukan ruang tamu yang simetris namun tidak monoton, penataan dapur agar tidak terletak disamping tangga, penataan posisi tangga untuk tidak berada di depan pintu masuk atau depan pintu kamar, dan perhitungan jumlah anak tangga.

Penataan posisi rumah juga merupakan hal yang perlu diperhatikan, terutama untuk rumah yang terletak pada posisi tikungan tajam, dan rumah yang terletak pada dua jalan konvergen, alangkah baiknya memberikan beberapa vegetasi disekitarnya. Selain itu pemilihan nomor rumah juga merupakan hal yang perlu diperhatikan, terutama menghindari rumah dengan unsur angka 4. 


\section{DAFTAR PUSTAKA}

Anindita, K., Setijanti, P., \& Rachmawati, M. (2014). "Feng Shui : Peran Non-Teknologi dalam Pemilihan Rumah Tinggal di Surabaya Timur ". Prosiding Seminar Nasional Manajemen Teknologi XX. February 1, 2014. Institut Teknologi Sepuluh November, Surabaya, Indonesia.

Bourassa, S.C., \& Peng, V.S. (1999). "Hedonic Price and House Numbers: The Influence of Feng Shui". International Real Estate Review Vol (2.),79-93.

Collins T.K. (2015). The Retail Recipe for Great Feng Shui. Western School of Fengshui. Retrieved from http://westernschooloffengshui.com/the-retail-recipe-for-great-fengshui/

Dian, M. (2012), "Feng Shui sebagai Ilmu Arsitektur Purba". Simposium Nasional Arsitektur dan Feng shui. Universitas Parahyangan, Bandung.

Harjanto, A. (2008). "12 Pedoman Feng Shui dalam Membeli dan Membangun Rumah : -Apa yang Harus Anda Ketahui ?." Indonesia Feng Shui Online Center. Retrieved August 5, 2016, from http://www.klikfengshui.com/free_product/12_pedoman.pdf

Harjanto, A. (2008). "Pedoman Feng Shui Eksterior". Indonesia Feng Shui Online Center. Retrieved December 2, 2016, from http://www.klikfengshui.com/free_product/Pedoman\%20Feng\%20Shui\%20Eksterior. php

Choy, H. (n.d). The 15 Core Principles of Feng Shui. European College of Feng Shui. Retrieved August 5, 2016, from http://www.fengshui-college.org/articles/the-15-coreprinciples-of-feng-shui\#_ftn1

Kurniawan, A.(2015). "Fengsh̆ui Based Marketing: Strategi Memenangkan Konsumen Berbasis Pemahaman Nilai-Nilai Kepercayaan Tionghoa". Performance 21(1), 48-57.

Roberts, S. (2006). Fast Feng Shui for Your Home Office. Lotus Pond Press.

Ziegler, H. (2001). Sell Your Home Faster with Feng Shui: Ancient Wisdom to Expedite the Sale of Real Estate. Dragon Chi Publication, Arroyo Grande, CA. 